\title{
Patient-level costs of major cardiovascular conditions: a review of the international literature
}

\section{Gina Nicholson' \\ Shravanthi R Gandra ${ }^{2}$ \\ Ronald J Halbert' \\ Akshara Richhariya ${ }^{2}$ \\ Robert J Nordyke'}

IICON, El Segundo, ${ }^{2}$ Amgen Inc., Thousand Oaks, CA, USA
Correspondence: Shravanthi R Gandra Amgen Inc., I Amgen Center Drive, Thousand Oaks, CA 91320, USA

$\mathrm{Tel}+$ I 8053 13 643 |

Email sgandra@amgen.com
This article was published in the following Dove Press journal:

ClinicoEconomics and Outcomes Research

21 September 2016

Number of times this article has been viewed

Objective: Robust cost estimates of cardiovascular (CV) events are required for assessing health care interventions aimed at reducing the economic burden of major adverse $\mathrm{CV}$ events. This review synthesizes international cost estimates of $\mathrm{CV}$ events.

Methods: MEDLINE database was searched electronically for English language studies published during 2007-2012, with cost estimates for CV events of interest - unstable angina, myocardial infarction, heart failure, stroke, and CV revascularization. Included studies provided at least one estimate of patient-level direct costs in adults for any identified country. Information on study characteristics and cost estimates were collected. All costs were adjusted for inflation to 2013 values.

Results: Across the 114 studies included, the average cost was US \$6,466 for unstable angina, $\$ 11,664$ for acute myocardial infarction, $\$ 11,686$ for acute heart failure, $\$ 11,635$ for acute ischemic stroke, $\$ 37,611$ for coronary artery bypass graft, and $\$ 13,501$ for percutaneous coronary intervention. The ranges for cost estimates varied widely across countries with US cost estimate being at least twice as high as European Union costs for some conditions. Few studies were found on populations outside the US and European Union.

Conclusion: This review showed wide variation in the cost of CV events within and across countries, while showcasing the continuing economic burden of CV disease. The variability in costs was primarily attributable to differences in study population, costing methodologies, and reporting differences. Reliable cost estimates for assessing economic value of interventions in CV disease are needed.

Keywords: cardiovascular diseases, health care costs, hospitalization economics, follow-up studies

\section{Introduction}

For decades, the broad class of cardiovascular diseases (CVD) has been the leading cause of mortality worldwide, responsible for $30 \%$ of all deaths ( $\sim 17$ million annually). ${ }^{1} \mathrm{CVD}$ is responsible for $>7.5$ million inpatient cardiovascular $(\mathrm{CV})$ procedures in the $\mathrm{US}^{2}$ and just $>2,500$ inpatient discharges per 100,000 persons in Europe. ${ }^{3}$ CVD places a significant economic burden on patients and health care systems. In 2010 , the direct medical costs of CVD totaled US \$272 billion in the US alone (2008 USD). ${ }^{2}$ In the European Union (EU), direct medical costs of CVD are estimated to reach $€ 106$ billion annually. ${ }^{4}$ The health care burden of CVD continues to grow with an aging population as well as the contribution of clinical risk factors, such as obesity, high-lipid levels, and consequent atherosclerosis and hypertension. 
The clinical complexity and extensive economic burden of CVD has led to a number of studies examining the costs of major CV conditions. As the standard of care for the treatment of $\mathrm{CV}$ conditions evolves, the cost of care also increases. A considerable literature focused on reviews of economic evaluations in CVD exists but few reviews on cost-of-illness (COI) studies in CVD have been published recently. The COI study reviews that have been published in the past 5 years have focused solely on costs of stroke. ${ }^{5,6}$ No review to date has synthesized international COI studies on all the major components of CVD. Reliable and recent cost estimates are necessary components of economic evaluations and decision making on reimbursement for $\mathrm{CV}$ interventions.

This review aims to summarize patient-level estimates from CVD COI studies published in English, between 2007 and 2012. CV events are expensive worldwide both in terms of direct medical costs at the time of event and through subsequent follow-up health care costs after the event. Therefore, the objectives of this review are to identify short-term (initial hospitalization) and follow-up (through 1 year after initial hospitalization) costs of each condition and identify gaps in the COI literature.

\section{Methods}

\section{Search strategy}

An electronic search of the published scientific literature was conducted to identify relevant cost studies for CV events of interest using PubMed to query the MEDLINE electronic bibliographic database. The review focused on English language studies published between January 1, 2007, and December 31, 2012. Each CV event MeSH term, such as "angina", "myocardial infarction (MI)", "stroke", "heart failure", "coronary revascularization", "peripheral arterial disease", and "cerebral revascularization", was paired with MeSH term "health care costs". Searches were otherwise limited to human studies published in English language only.

\section{Selection criteria}

Original studies providing patient-level cost estimates for any condition identified in the search strategy were included. Review articles were excluded, but reference lists of review articles were hand searched for relevant original studies. No restriction was made on the country of origin. Costeffectiveness studies of specific interventions and treatments were excluded due to specificity of the patient population and treatment arms, which are unlikely to be generalizable to overall cost estimates. Additional exclusion criteria were as follows: 1) population size $<100$ patients, 2) studies on child or adolescent populations, and 3) studies providing only indirect medical costs or population-level costs. Table 1 presents the selection criteria for this review.

This article focuses on the subset of studies evaluating the following CV events: unstable or unspecified angina, MI, ischemic or unspecified stroke, heart failure, and coronary revascularization procedures. Studies without cost estimates in one of these categories were excluded from this review.

\section{Study selection}

Four reviewers reviewed all abstracts against eligibility criteria. Abstracts selected for full-text review by the reviewers were retrieved. One reviewer reassessed the full list of abstracts recommended for inclusion. Full-text review was conducted by four reviewers to assess eligibility for abstractions. Any disagreements were adjudicated by discussion. Abstract and full-text review was conducted using Microsoft Excel software.

Table I Selection criteria for studies of cardiovascular event costs

\begin{tabular}{|c|c|}
\hline Domain & Inclusion criteria \\
\hline Population & Adults (18+ years) \\
\hline \multirow[t]{3}{*}{ Intervention } & $\begin{array}{l}\text { Primary prevention interventions aimed at lowering } \\
\text { cholesterol }\end{array}$ \\
\hline & Secondary prevention of cardiovascular events \\
\hline & Burden of disease analyses \\
\hline \multirow[t]{2}{*}{ Outcomes } & $\begin{array}{l}\text { Direct medical costs of cardiovascular events listed } \\
\text { in review question }\end{array}$ \\
\hline & $\begin{array}{l}\text { Must report cost (modeled or primary) for } \\
\text { requested cardiovascular event }\end{array}$ \\
\hline Timing & No restriction on time horizon \\
\hline Setting & All countries \\
\hline \multirow[t]{4}{*}{ Study design } & Randomized controlled trials \\
\hline & Prospective or retrospective observational studies \\
\hline & Systematic reviews with or without meta-analyses \\
\hline & (for hand searching primary articles) \\
\hline Publication dates & January 2007-December 2012 \\
\hline Language & English \\
\hline Domain & Exclusion criteria \\
\hline \multirow[t]{5}{*}{ Population } & Children $(<18$ years $)$ \\
\hline & Sample size $(\mathrm{N}<100)$ \\
\hline & Adults with congenital heart conditions \\
\hline & Adults with traumatic brain injuries \\
\hline & Brain aneurysms \\
\hline \multirow[t]{7}{*}{ Intervention } & Primary prevention interventions not aimed at \\
\hline & lowering cholesterol (eg, smoking cessation) \\
\hline & Disease management studies \\
\hline & Cost-effectiveness studies* \\
\hline & HTA submissions* \\
\hline & Trials of diagnostic therapies \\
\hline & Screening or monitoring trials \\
\hline Outcomes & $\begin{array}{l}\text { Indirect medical costs (eg, absenteeism and } \\
\text { caregiver burden) }\end{array}$ \\
\hline
\end{tabular}

Note: ${ }^{*}$ Cost-effectiveness studies and health technology assessment submissions were excluded in the original search strategy protocol for this project. However, results from a separate literature review examining statin cost-effectiveness trials have been incorporated in this report.

Abbreviation: HTA, health technology assessment. 


\section{Data extraction and synthesis}

Titles and abstracts were screened to assess relevance of the study to review. Relevant full-text articles were obtained for study, and cost estimates and methodology as reported by authors were abstracted. Though no formal assessment of quality was undertaken, study design, sample sizes, and presence of precision estimates (eg, standard deviation) were abstracted to give context to cost estimates. Cost estimates derived from hospital charges unconverted to costs were collected but not abstracted. Thus, articles where only hospital charge data were reported are not included in this article. Cost estimates may be calculated based on a number of methods: reimbursement-based methods, eg, Medicare Diagnosis-Related Groups, top-down methods, and bottomup methods. We have included the inclusion population and study design in Supplementary material. Costs for patients with comorbidities or other subpopulations were collected and abstracted. Where possible, only inpatient cost estimates provided by authors were abstracted for comparison between studies. If inpatient costs were not available, costs as reported by study authors and the type of cost recorded were included. Studies were stratified by the type of cost as follows:

- Acute cost: inclusive of a procedure or initial hospitalization,

- Follow-up cost: inclusive of rehospitalization episodes. second procedures, continuing care after initial procedure, hospitalization, or routine care, occurring from the day after discharge until 1 year after an event.

- End-of-life cost: specific to the period immediately preceding death (for heart failure studies only).

All costs were inflated to 2013 values in each country's currency utilizing the medical component of the Consumer Price Index. ${ }^{7}$ Costs were then adjusted to international dollars using the 2013 purchasing power parity index. ${ }^{8}$ Currency year as reported by author was utilized for inflation to 2013 values; if authors did not specify the currency year, the latest source data year was used for inflation. If source data year was not specified, the study publication year was used for inflation.

\section{Results}

The search identified 1,178 abstracts. Of these abstracts, 252 (21\%) abstracts were retrieved for full-text review. The bibliographies of systematic reviews were searched, yielding an additional seven studies, for a total of 259 studies reviewed. Of the 259 studies retrieved, 83 studies were discarded for having an excluded study design (eight studies), indirect costs or population costs only (22 studies), no event cost estimate
(33 studies), review articles (twelve studies), and a sample size of $<100$ patients (eight studies). A total of 176 studies were abstracted after full-text review (Figure 1).

Due to the breadth of the results, this article focuses on studies evaluating the following CV events: unstable or unspecified angina, MI, ischemic or unspecified stroke, heart failure, and coronary revascularization procedures, for which 114 studies ( $65 \%$ of abstracted studies) were abstracted.

\section{Study characteristics}

Included studies provided estimates from 26 countries, with more than half of studies based on US population samples $(\mathrm{n}=60 ; 53 \%)$, followed by UK $(\mathrm{n}=10 ; 9 \%)$, Germany $(\mathrm{n}=7$; $6 \%$ ), and Sweden ( $\mathrm{n}=6 ; 6 \%)$, (Table 2). Mean costs for coronary revascularization procedures were found in 48 studies, with ischemic stroke estimates found in 32 studies. Two US studies ${ }^{9,10}$ and one EU study ${ }^{11}$ provided cost estimates for all events of interest. Cost estimates were aggregated by region, based on the presence of two or more studies in a geographical area. A list of the full population and study design characteristics of each included study is provided in Supplementary material.

\section{Cost reporting}

Costs were categorized based on the authors' reported cost components. Only direct medical costs were abstracted from the studies and classified into either acute (inpatient hospitalization for event) or follow-up (after discharge for initial event). All inpatient costs were abstracted based on authors' definition of a hospitalization for treatment of a defined CV event, regardless of the length of stay. Length of hospitalization stay was not assessed in this article. For comparison, only follow-up costs through the first year after initial event were abstracted.

Costs were categorized for each CV event, as defined by the authors. We have separately identified costs for procedures (coronary bypass graft surgery [CABG] and percutaneous coronary intervention [PCI]) and hospitalizations due to causal events (unstable angina and MI), based on how the authors identified the costs in the article. Therefore, cost estimates for unstable angina or MI events may potentially include embedded revascularization components that were not identified as a separate cost component.

\section{Source data}

Source data were identified through methods indicated by study authors in the following five study designs: claims database analyses, disease registry studies, population-based 


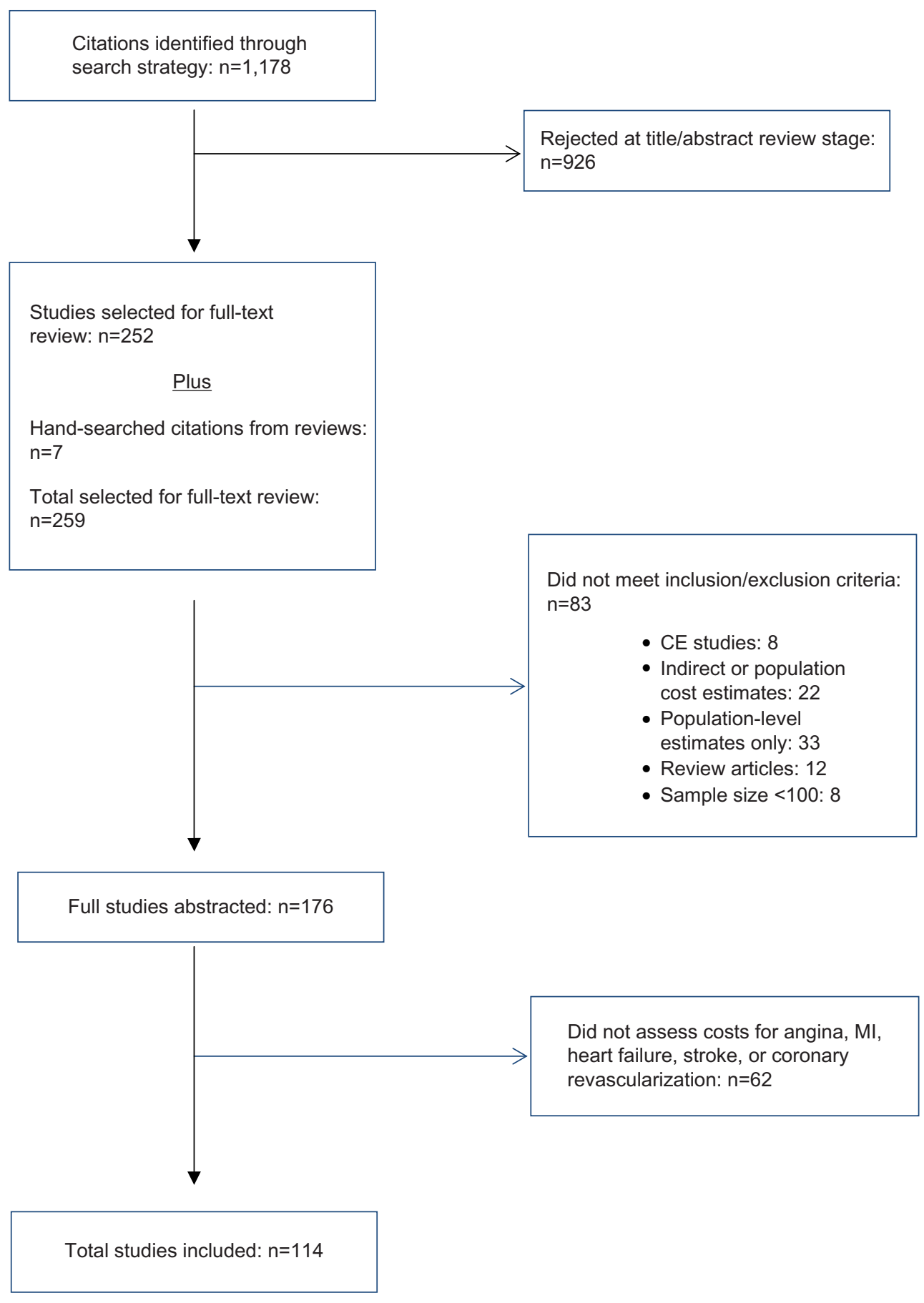

Figure I Workflow of included studies.

Abbreviations: $\mathrm{Ml}$, myocardial infarction; $\mathrm{CE}$, cost-effectiveness.

registry studies, retrospective cohorts from a single hospital, and a randomized control trial (RCT). Claims data analyses were utilized in US-based 46 studies (39\%): retrospective and prospective hospital cohorts were utilized in 35 studies (30\%), and disease-specific registries were utilized in 16 studies (14\%). RCT economic substudies were the basis of 16 studies (14\%) (Table 2). Studies predominantly used source data collected within the past 10 years (2003 or later). Only
14 studies (12\%) reported cost estimates where all data were collected before 2003 .

\section{Comorbidity and history of event subgroups}

Though several studies ( $\mathrm{n}=37 ; 32 \%)$ used multivariate models to assess cost predictors, only 21 (18\%) studies provided cost estimates among high-risk patients (such as patients with 
Table 2 Summary of characteristics of cost-of-illness study

\begin{tabular}{|c|c|}
\hline Study characteristics & Number of studies \\
\hline \multicolumn{2}{|l|}{$\mathrm{CV}$ event $\cos ^{\mathrm{a}}$} \\
\hline Coronary revascularization & 48 \\
\hline Unstable angina & 8 \\
\hline Heart failure & 29 \\
\hline Ischemic stroke & 32 \\
\hline Myocardial infarction & 18 \\
\hline \multicolumn{2}{|l|}{ Source data type $\mathrm{a}^{\mathrm{a}}$} \\
\hline Claims database & 46 \\
\hline Disease registry & 16 \\
\hline Hospital cohort & 35 \\
\hline Population registry & 9 \\
\hline Randomized controlled trial & 16 \\
\hline \multicolumn{2}{|l|}{ Region } \\
\hline \multicolumn{2}{|l|}{ Asia } \\
\hline People's Republic of China & 5 \\
\hline Japan & 3 \\
\hline Singapore & I \\
\hline Taiwan & I \\
\hline Thailand & 2 \\
\hline Australia & I \\
\hline Global & 3 \\
\hline \multicolumn{2}{|l|}{ Latin America } \\
\hline Argentina & 4 \\
\hline Brazil & 4 \\
\hline \multicolumn{2}{|l|}{ Europe } \\
\hline Belgium & 3 \\
\hline Denmark & 1 \\
\hline Estonia & 1 \\
\hline Finland & 4 \\
\hline France & 5 \\
\hline Germany & 7 \\
\hline Greece & 2 \\
\hline Hungary & 1 \\
\hline The Netherlands & 2 \\
\hline Poland & I \\
\hline Spain & 6 \\
\hline Sweden & 6 \\
\hline Switzerland & 3 \\
\hline Turkey & I \\
\hline UK & 10 \\
\hline \multicolumn{2}{|l|}{ Middle East } \\
\hline Iran & 1 \\
\hline \multicolumn{2}{|l|}{ North America } \\
\hline Canada & 6 \\
\hline US & 60 \\
\hline
\end{tabular}

Note: ${ }^{a} \mathrm{~A}$ study may be counted more than once if it provides estimates in more than one country for more than $\mathrm{CV}$ event or if it uses multiple data sources. Abbreviation: $\mathrm{CV}$, cardiovascular.

comorbidities and a history of the event). Diabetics were the most prominent subgroup, with cost estimates found in five studies. Costs among patients with a history of the $\mathrm{CV}$ event were provided in four studies (Figure 2).

\section{Costs of unstable angina hospitalization}

In the US, two studies reported acute hospitalization costs, with an average of $\$ 7,916$ (median: $\$ 7,841$ ), ${ }^{9,10}$ with a slightly higher estimate for diabetics $(\$ 8,032) .{ }^{10}$ Outside the US, acute costs for angina were only found in a Thai hospital cohort of acute coronary syndrome patients $(\$ 2,893)$ (Table 3). ${ }^{12}$

Of the three studies reporting follow-up costs, two studies were US claims analyses ${ }^{10,13,14}$ and one study was a Swiss population registry. ${ }^{15}$ Costs ranged from $\$ 9,282$ for rehospitalization among diabetics ${ }^{10}$ to $\$ 28,509$ in attributable costs at 1 year. ${ }^{13}$ One-year follow-up costs in the only European study, a Swiss population registry, averaged $\$ 18,224 .{ }^{15}$

\section{Costs of MI}

Of 18 studies on MI, eight (44\%) studies were conducted in the US. . $10,13,16,17-20$ Nine studies assessed data from one or more European countries (50\%). ${ }^{11,15,21-27}$ Outside the US and Europe, two cost estimates were found in a Thai cohort of acute coronary syndrome patients ${ }^{12}$ and an Australian CVD registry. ${ }^{28}$

Over all studies, the mean cost of an acute MI was \$11,664 (median: \$7,324). Cost of acute hospitalization for MI ranged from $\$ 547$ in Hungary ${ }^{21}$ to $\$ 30,021$ for US diabetics. ${ }^{10}$ In the US, the mean cost of acute MI was $\$ 24,695$ (median: \$26,749). Cost estimates of acute MI averaged \$5,966 (median: \$6,749) in Europe and \$11,682-\$12,006 among diabetics based on a Swedish registry. ${ }^{26}$

An average cost of follow-up over a 1-year period was $\$ 32,379$ (median: $\$ 27,430$ ) based on three US claims analy$\operatorname{ses}^{10,13,20}$ and one Swiss registry analysis (Table 4$) .{ }^{15}$

\section{Costs of heart failure}

Heart failure costs were abstracted from 28 studies, mostly using US data $(\mathrm{n}=23 ; 79 \%)$. ${ }^{9,10,16,30-49}$ Three economic substudies of multicountry RCT populations also included US samples. ${ }^{50-52}$ One Argentinian hospital cohort, ${ }^{53}$ a Canadian hospital cohort, ${ }^{54}$ and a Thai hospital cohort ${ }^{55}$ are the only studies with cost estimates outside the US.

The average cost of an acute heart failure hospitalization across all studies was $\$ 11,686$ (median: $\$ 10,291$ ). Costs ranged from $\$ 529$ in the Argentinian hospital cohort $^{53}$ to $\$ 27,006$ in a US claims analysis of patients aged 18-64 years. ${ }^{43}$ Acute costs for diabetics were found in one US claims analysis $(\$ 12,757) .{ }^{10}$ Follow-up costs through 1 year were estimated at $\$ 12,931$ (median: $\$ 15,238$ ), comprised solely of US studies. No follow-up costs were found in European studies. End-of-life costs (past 6 months) were estimated at an average $\$ 23,606$ based on a US Medicare claims analysis and a Canadian registry cohort (Table 5). ${ }^{38,54}$ 


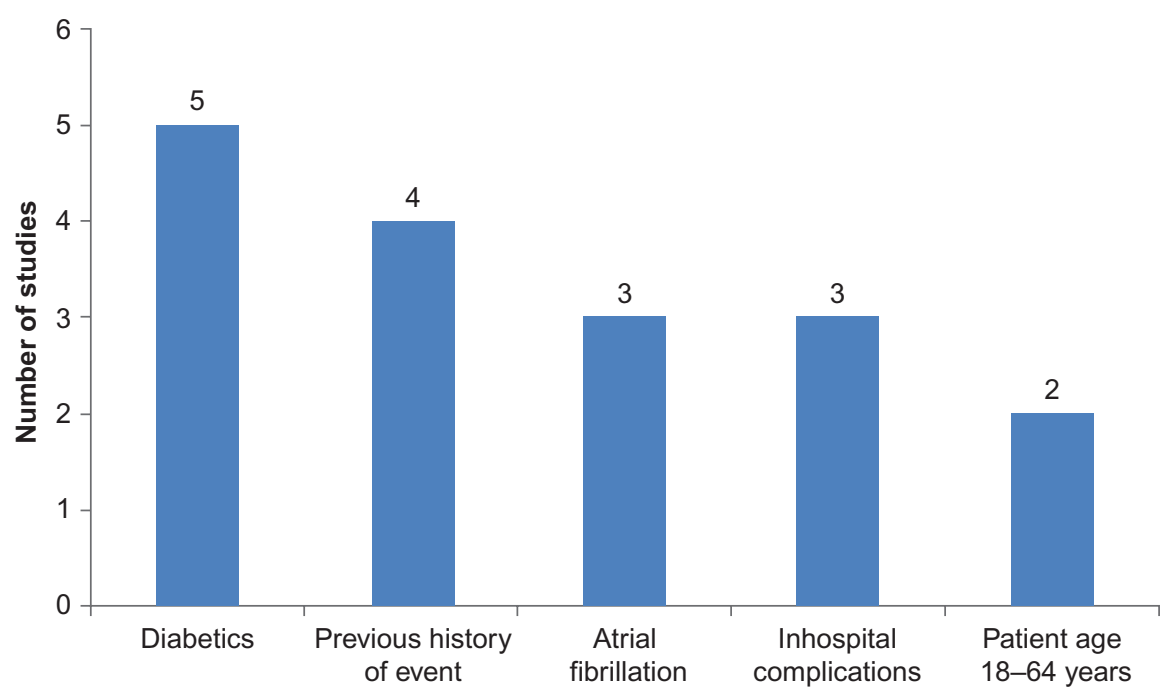

Figure 2 Number of studies with comorbid patient populations or subgroup cost estimates.

Table 3 Average cost of angina across all reported studies

\begin{tabular}{llll}
\hline Time horizon & Mean cost & Median cost & Range \\
\hline Acute $^{\mathrm{a}}$ & $\$ 6,821$ & $\$ 7,859$ & Number of studies \\
US only & $\$ 7,916$ & $\$ 7,841$ & 3 \\
Follow-up through I year & $\$ 2,893-\$ 8,032$ & $\$ 7,841-\$ 8,032$ \\
US only & $\$ 17,015$ & $\$ 18,224$ & $\$ 9,282-\$ 28,509$ \\
\hline
\end{tabular}

Notes: aUS acute estimates plus Thai estimate. ${ }^{b}$ All US follow-up estimates plus Swiss estimate. Costs are shown in US\$.

Table 4 Average cost of myocardial infarction across all reported studies

\begin{tabular}{lllll}
\hline Time horizon & Mean cost & Median cost & Range & Number of studies \\
\hline Acute $^{\mathrm{a}}$ & $\$ 11,664$ & $\$ 7,324$ & $\$ 547-\$ 30,021$ & 18 \\
US only & $\$ 24,695$ & $\$ 26,749$ & $\$ 17,346-\$ 30,021$ & 7 \\
EU only & $\$ 5,966$ & $\$ 6,749$ & $\$ 547-\$ 10,435$ & 9 \\
Western & $\$ 5,025$ & $\$ 6,749$ & $\$ 3,957-\$ 7,842$ & 2 \\
Northern & $\$ 6,747$ & $\$ 6,852$ & $\$ 3,435-\$ 9,849$ & 3 \\
Eastern & $\$ 992$ & $\$ 992$ & $\$ 547-\$ 1,437$ & 2 \\
Southern & $\$ 7,386$ & $\$ 8,270$ & $\$ 2,569-\$ 10,435$ & 3 \\
Follow-up through I year ${ }^{b}$ & $\$ 32,379$ & $\$ 27,430$ & $\$ 28,777-\$ 60,857$ & 4 \\
US only & $\$ 34,463$ & $\$ 26,082$ & $\$ 22,264-\$ 60,857$ & 3 \\
\hline
\end{tabular}

Notes: European regions are based on the United Nations Statistics Division categories. ${ }^{29}$ aAll acute estimates plus Australian and Thai estimates. ${ }^{\mathrm{b}} \mathrm{All}$ US follow-up estimates plus Swiss estimate. Costs are shown in US\$.

Abbreviation: EU, European Union.

\section{Costs of ischemic stroke}

Cost estimates for ischemic or unspecified stroke were abstracted from 32 studies. US ( $\mathrm{n}=13 ; 41 \%),{ }^{9}, 10,13,19,34,56-63$ European $(n=12 ; 38 \%),{ }^{11,26,64-73}$ and Asian $(n=4 ; 13 \%)^{74-77}$ cost estimates comprise the majority of studies, along with two Latin American hospital cohorts, ${ }^{78,79}$ a Canadian RCT, ${ }^{80}$ and an Australian registry. ${ }^{28}$ All but one of the US studies found analyzed claims data for cost estimates; the remaining US study provided cost estimates from a US CVD registry. ${ }^{61}$ Half of European estimates $(n=6)$ were based on hospital cohorts with the other half from disease/population registries.

Across all studies, the average cost of an acute ischemic stroke hospitalization was $\$ 11,635$ (median: $\$ 8,097$ ). In the
US, the mean cost was higher at $\$ 18,543$ (median: $\$ 18,296$ ). Costs in the US ranged from $\$ 8,069$ in a Medicare claims analysis ${ }^{60}$ to $\$ 38,231$ in young patients (aged $18-44$ years). ${ }^{56}$ Acute stroke cost was $\$ 13,469$ for patients with diabetes ${ }^{10}$ and $\$ 20,303$ for patients with a previous stroke or transient ischemic attack. ${ }^{58}$ The average cost of acute ischemic stroke across Europe was $\$ 11,900$, with a low estimate of $\$ 5,016$ in a German hospital cohort ${ }^{72}$ and a high estimate of $\$ 24,451$ in a Scottish population registry. ${ }^{63}$ Acute costs for diabetics were found in one Swedish regional registry $(\$ 21,060) .{ }^{26}$ One-year follow-up costs averaged $\$ 13,683$ (median: $\$ 10,248$ ), with a European average of $\$ 3,720$ and a US average of $\$ 17,819$ (Table 6). 
Table 5 Average cost of heart failure across all reported studies

\begin{tabular}{lllll}
\hline Time horizon & Mean cost & Median cost & Range & Number of studies \\
\hline Acute $^{\mathrm{a}}$ & $\$ 1 \mathrm{I}, 686$ & $\$ 10,291$ & $\$ 529-\$ 27,006$ & 12 \\
US only & $\$ 12,383$ & $\$ 10,667$ & $\$ 5,343-\$ 27,006$ & 11 \\
Follow-up through I year & $\$ 12,931$ & $\$ 15,238$ & $\$ 2,258-\$ 24,084$ & 7 \\
Follow-up through I year (inpatient costs only) & $\$ 11,584$ & $\$ 15,238$ & $\$ 2,258-\$ 19,844$ & 6 \\
End of life costs (past 6 months) $^{\mathrm{b}}$ & $\$ 23,606$ & $\$ 23,606$ & $\$ 19,637-\$ 27,574$ & 2 \\
\hline
\end{tabular}

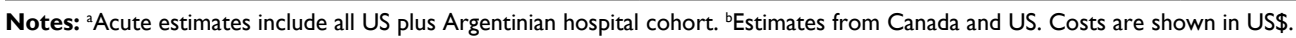

Table 6 Average cost of ischemic stroke across all reported studies

\begin{tabular}{lllll}
\hline Time horizon & Mean cost & Median cost & Range & Number of studies \\
\hline Acute $^{\mathrm{a}}$ & $\$ 11,635$ & $\$ 8,097$ & $\$ 1,077-\$ 38,231$ & 21 \\
US only & $\$ 18,543$ & $\$ 18,296$ & $\$ 8,069-\$ 38,231$ & 6 \\
EU only & $\$ 11,900$ & $\$ 8,325$ & $\$ 5,016-\$ 24,451$ & 8 \\
Western & $\$ 10,230$ & $\$ 7,520$ & $\$ 5,016-\$ 21,060$ & 4 \\
Northern & $\$ 17,776$ & $\$ 20,018$ & $\$ 8,858-\$ 24,451$ & 3 \\
Asia only & $\$ 4,183$ & $\$ 3,508$ & $\$ 1,077-\$ 8,097$ & 3 \\
Latin America only & $\$ 3,388$ & $\$ 3,388$ & $\$ 2,225-\$ 4,550$ & 2 \\
Follow-up through I year ${ }^{\mathrm{b}}$ & $\$ 13,683$ & $\$ 10,248$ & $\$ 1,169-\$ 52,333$ & 13 \\
EU only & $\$ 3,720$ & $\$ 2,133$ & $\$ 1,169-\$ 10,248$ & 4 \\
US only & $\$ 17,819$ & $\$ 16,547$ & $\$ 2,362-\$ 52,333$ & 9 \\
Follow-up through I year (inpatient costs only) ${ }^{\mathrm{c}, \mathrm{d}}$ & $\$ 6,819$ & $\$ 5,128$ & $\$ 1,169-\$ 20,169$ & 9 \\
\hline
\end{tabular}

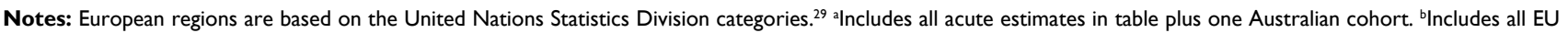
estimates plus Greek estimate. Includes all US and EU estimates plus Singapore estimate. 'Estimates of rehabilitation care are included in inpatient costs. Costs are shown in US\$.

Abbreviation: EU, European Union.

\section{Costs of coronary revascularization}

Forty-eight studies provided estimates on a coronary revascularization procedure - $\mathrm{CABG}, \mathrm{PCI}$, and a hybrid CABG-PCI procedure. Nearly half of the study estimates on revascularization were based on US populations $(n=24$; $48 \%) ;^{9,10,13,81-102}$ the remainder came from eleven European $(23 \%),{ }^{103-113}$ six Asian (13\%), ${ }^{11-119}$ three Latin American studies $(6 \%),{ }^{120-122}$ and three multicountry RCTs $(6 \%) .{ }^{123-125}$ Hospital cohorts $(n=19 ; 40 \%)$, claims analyses $(n=14 ; 29 \%)$ and RCTs $(n=10 ; 20 \%)$ were the predominant methodologies for revascularization estimates.

CABG cost in the US averaged $\$ 57,577$ (median: $\$ 61,445$ ) with a range of cost estimates from $\$ 17,731$ to $\$ 124,221$ in eleven studies. Average CABG cost in Europe was $\$ 14,562$ (median: $\$ 13,732$ ) with a range of costs from $\$ 924$ to $\$ 27,724$ in four studies. There were too few studies to allow aggregation of CABG cost in Asia or elsewhere (Table 7).

Overall cost of PCI across all studies was $\$ 13,501$ (median: $\$ 14,025)$ ranging from $\$ 520$ in the multicountry $\mathrm{RCT}^{123}$ to $\$ 25,641$ in a US-managed care claims analysis. ${ }^{83}$ PCI cost in Europe $(\$ 12,208$; median: $\$ 11,296)$ and Asia $(\$ 11,717$; median: $\$ 11,739)$ were comparable but based on only three studies each. PCI cost in the US was estimated at \$20,146 (median: \$19,429) based on six studies. Mean PCI costs in the US $(\$ 20,146)$ were nearly one-third of the mean CABG costs in US studies $(\$ 57,577)$. Mean CABG costs in
Europe, however, were only slightly higher $(\$ 14,562)$ than PCI costs $(\$ 12,208)$ (Table 7).

\section{Discussion}

Previous reviews evaluating patient-level costs of care have focused on the cost burden of single components of CVD, such as stroke. These reviews have reported significant variation in cost estimates. Prior assessment of the ischemic stroke literature by Luengo-Fernandez et $\mathrm{al}^{6}$ found 20 -fold difference in US costs of ischemic stroke $(\$ 468-\$ 146,149)$ and a mean cost of $\$ 19,018$. A review of COI from Demaerschalk et $\mathrm{al}^{5}$ reported a narrower range of $\$ 8,000-\$ 23,000$ (2008 USD) for acute care costs in the US and 1-year follow-up costs of care from $\$ 15,102$ to $\$ 30,000$. An earlier analysis of follow-up stroke costs among Western countries (US, Australia, Western Europe, and New Zealand) reported annual follow-up costs ranging from $\$ 7,975$ to $\$ 54,546$ (1998 USD). ${ }^{126}$ Only one study assessing chronic angina COI studies was identified, with reported annual costs of treatment in the US from $\$ 2,569$ (1995 USD) to $\$ 7,207$ (1992 USD). ${ }^{127}$

The mean cost of stroke found in this review, $\$ 18,543$ in the US and $\$ 11,900$ in Europe, are in-line with findings in previous reviews, with a fourfold variation between studies in this review comparable to prior work. For other $\mathrm{CV}$ events, substantial variation in cost estimates within regions was evident. For follow-up costs, estimate differentials may 
Table 7 Average cost of coronary revascularization over all reported studies

\begin{tabular}{lllll}
\hline Time horizon & Mean cost & Median cost & Range & Number of studies \\
\hline Acute CABG & $\$ 37,611$ & $\$ 28,512$ & $\$ 249-\$ 124,221$ & 24 \\
US only & $\$ 57,577$ & $\$ 61,445$ & $\$ 17,731-\$ 124,221$ & 11 \\
EU only & $\$ 14,562$ & $\$ 13,732$ & $\$ 924-\$ 27,724$ & 4 \\
Latin America only & $\$ 3,331$ & $\$ 3,331$ & $\$ 2,836-\$ 3,826$ & 2 \\
Acute PCl & $\$ 13,501$ & $\$ 14,025$ & $\$ 520-\$ 25,641$ & 14 \\
US only & $\$ 20,146$ & $\$ 19,429$ & $\$ 16,104-\$ 25,641$ & 6 \\
EU only & $\$ 12,208$ & $\$ 11,296$ & $\$ 8,068-\$ 18,173$ & 3 \\
Asia only & $\$ 11,717$ & $\$ 11,739$ & $\$ 9,383-\$ 14,029$ & 3 \\
Follow-up through I year - PCI & $\$ 11,012$ & $\$ 6,017$ & $\$ 1,686-\$ 33,964$ & 4 \\
Follow-up through I year - CABG & $\$ 28,903$ & $\$ 36,045$ & $\$ 1,170-\$ 49,494$ & 3 \\
\hline
\end{tabular}

Note: Costs are shown in US\$.

Abbreviations: CABG, coronary bypass graft surgery; EU, European Union; $\mathrm{PCl}$, percutaneous coronary intervention.

likely be the result of follow-up length; a 6-month follow-up period and a 1-year follow-up period will necessarily have much different cost estimates attached. Acute cost estimates, however, had significant variation as well. In the EU, cost estimates for MI varied 19-fold, and a CABG procedure varied 30-fold. Similarly, high estimates for CABG costs were seven times higher than the lowest cost in the US and eight times higher than the lowest cost in Asia. Acute costs for $\mathrm{CABG}$ procedures, in particular, have outpaced other $\mathrm{CV}$ event costs.

Follow-up event costs, comprised largely from US studies, were found to be as high as acute costs, or in the case of MI nearly three times higher than acute costs. Care in the year following an acute episode, therefore, may be an important lever in the reduction of the economic burden of CVD. However, follow-up length varied widely from 30 days posthospitalization to 1 year posthospitalization. Different cost components may have been reported in various studies, such as inpatient, outpatient, medication, and rehabilitation care, and the cost components included in calculating the reported cost estimate were not always clearly reported by the authors. Reporting differences add to the variability in estimates.

This is the first review as far as the authors are aware that synthesizes the costs of multiple CV conditions from COI studies. The present review reports costs from COI studies evaluating all major $\mathrm{CV}$ events and conditions reported globally from 2007 to 2012 . As evidenced by the findings in this review, the worldwide cost burden of CVD remains significant. Though comparison of results is hampered by the differences in study design, several themes emerge. The findings of the literature suggest that in the US and Europe, revascularization procedures and $\mathrm{MI}$ are $\mathrm{CV}$ events with the highest acute costs. Though fewer studies are available, costs of revascularization procedures throughout Asia are also higher than other reported event costs. Costs in the US remain higher than other countries, though significant variation within the US and other regions was found. Methodological cost accounting, setting, and population differences may account for some of this variation. Less variation was seen among European estimates, with the exception of the cost of MI in Eastern Europe, which was reported much lower compared to the rest of Europe (\$992 versus $\$ 5,966$ across EU).

Subgroup cost estimates were not widely available in this literature. Cost estimates across all events were reported in only one US study. ${ }^{10}$ Based on this study alone, costs among diabetic population appeared to be slightly higher than the cost among the general population. More research on this and other high-risk populations, including patients with a history of a CV event or a previous CV event, is needed.

Though the broad scope of this literature review was intended, several limitations remain. This review is intended as a descriptive, narrative summary of global cost studies, and as such no quantitative methods to assess effect size are calculated. Cost-effectiveness models were excluded from the selection criteria for this review due to very specific treatments and patient population inherent in those studies. As a result, additional literature or submissions to governing bodies assessing costs of care for specific therapies or treatments published outside of MEDLINE is not provided in this review. Cost estimates for any comorbidity are included for abstraction in this review. Although comorbid conditions may increase costs, patients with multiple conditions portray "real-world" patient populations. We did not stratify costs by the severity of conditions, largely due to methodological differences in reporting by study authors. An assessment of country-specific patient-level costs by, eg, patients with ST elevation MI versus those without would add significantly to the economic burden literature. This review included English language literature only, and therefore, some cost estimates in other languages may have been missed. Finally, we did not include cost-effectiveness analyses in these results, and additional robust data may be found in that literature. Though 
differences in study design were noted, the quality of each study design was not formally addressed.

Country-specific cost estimates are integral to health care decision making. Findings from this review indicate that a majority of evidence was collected in the US and Europe, and a dearth of patient-level cost estimates remains in other global regions. This review attempted to locate studies in any country available; yet a dearth of patient-level cost estimates outside the US and Europe remain unclear. Wide variation in cost estimates underscores the need for more reliable estimates of CV conditions, not only within the US but also globally. Given the importance and potential implications of these COI studies, standardized and endorsed protocols for the estimation of costs will facilitate comparison across countries and illnesses. The absence of specific guidelines for measurement in COI studies will continue to hamper efforts to compare estimates across studies.

\section{Acknowledgment}

This study was sponsored by Amgen, Inc.

\section{Disclosure}

Shravanthi R Gandra is employed by Amgen, Inc., and Akshara Richarriya was previously employed by Amgen, Inc., at the time this work was completed. At the time this work was completed, Robert J Nordyke, Ronald J Halbert, and Gina Nicholson were employed by ICON plc, which was a paid consultant to Amgen, Inc., in the development of this article. The authors report no other conflicts of interest in this work.

\section{References}

1. World Health Organization [webpage on the Internet]. Cardiovascular Diseases (CVD) Fact Sheet. 2013. Available from: http://www.who. int/mediacentre/factsheets/fs317/en/index.html. Accessed April 20, 2013.

2. Laslett LJ, Alagona P Jr, Clark BA 3rd, et al. The worldwide environment of cardiovascular disease: prevalence, diagnosis, therapy, and policy issues: a report from the American College of Cardiology. $J$ Am Coll Cardiol. 2012;60(25 suppl):S1-S49.

3. Nichols M, Townsend N, Scarborough P, Rayner M. Cardiovascular disease in Europe: epidemiological update. Eur Heart $J$. 2013;34(39):3028-3034.

4. European Heart Network [webpage on the Internet]. European Cardiovascular Disease Statistics. 2012. Available from: http://www. ehnheart.org/cvd-statistics.html. Accessed October 14, 2013.

5. Demaerschalk BM, Hwang HM, Leung G. US cost burden of ischemic stroke: a systematic literature review. Am J Manag Care. 2010;16(7): 525-533.

6. Luengo-Fernandez R, Gray AM, Rothwell PM. Costs of stroke using patient-level data: a critical review of the literature. Stroke. 2009;40(2): e18-e23.

7. United States Bureau of Labor Statistics [webpage on the Internet]. Consumer Price Index. Current Series. 2013. Available from: http:// www.bls.gov/cpi/data.htm. Accessed October 23, 2013.
8. World Bank [webpage on the Internet]. PPP conversion factor, GDP (LCU per international \$). 2015. Available from: http://data.worldbank.org/indicator/PA.NUS.PPP. Accessed February 16, 2015.

9. Chapman RH, Liu LZ, Girase PG, Straka RJ. Determining initial and follow-up costs of cardiovascular events in a US managed care population. BMC Cardiovasc Disord. 2011;11:11.

10. Straka RJ, Liu LZ, Girase PS, DeLorenzo A, Chapman RH. Incremental cardiovascular costs and resource use associated with diabetes: an assessment of 29,863 patients in the US managed-care setting. Cardiovasc Diabetol. 2009;8:53.

11. Holstenson E, Ringborg A, Lindgren P, et al. Predictors of costs related to cardiovascular disease among patients with atrial fibrillation in five European countries. Europace. 2011;13(1):23-30.

12. Moleerergpoom W, Kanjanavanit R, Jintapakorn W, Sritara P. Costs of payment in Thai acute coronary syndrome patients. J Med Assoc Thai. 2007;90(suppl 1):21-31.

13. O'Sullivan AK, Rubin J, Nyambose J, Kuznik A, Cohen DJ, Thompson D. Cost estimation of cardiovascular disease events in the US. Pharmacoeconomics. 2011;29(8):693-704.

14. Miller CD, Hwang W, Case D, et al. Stress CMR imaging observation unit in the emergency department reduces 1-year medical care costs in patients with acute chest pain: a randomized study for comparison with inpatient care. JACC Cardiovasc Imaging. 2011;4(8):862-870.

15. Wieser S, Ruthemann I, De Boni S, et al. Cost of acute coronary syndrome in Switzerland in 2008. Swiss Med Wkly. 2012;142:w13655.

16. Naccarelli GV, Johnston SS, Lin J, Patel PP, Schulman KL. Cost burden of cardiovascular hospitalization and mortality in ATHENA-like patients with atrial fibrillation/atrial flutter in the United States. Clin Cardiol. 2010;33(5):270-279.

17. Timbie JW, Normand SL. A comparison of methods for combining quality and efficiency performance measures: profiling the value of hospital care following acute myocardial infarction. Stat Med. 2008;27(9): 1351-1370.

18. Schreyogg J, Stargardt T. The trade-off between costs and outcomes: the case of acute myocardial infarction. Health Serv Res. 2010;45(6 pt 1): $1585-1601$.

19. Hasan O, Orav EJ, Hicks LS. Insurance status and hospital care for myocardial infarction, stroke, and pneumonia. J Hosp Med. 2010;5(8): 452-459.

20. Kruse GB, Polsky D, Stuart EA, Werner RM. The impact of hospital pay-for-performance on hospital and Medicare costs. Health Serv Res. 2012;47(6):2118-2136.

21. Tiemann O. Variations in hospitalisation costs for acute myocardial infarction - a comparison across Europe. Health Econ. 2008;17(1 suppl):S33-S45.

22. Hakkinen U, Chiarello P, Cots F, Peltola M, Ratto H; EuroDRG Group. Patient classification and hospital costs of care for acute myocardial infarction in nine European countries. Health Econ. 2012;21(suppl 2): $19-29$.

23. Hakkinen U, Hartikainen J, Juntunen M, Malmivaara A, Peltola M, Tierala I. Analysing current trends in care of acute myocardial infarction using PERFECT data. Ann Med. 2011;43(suppl 1):S14-S21.

24. Gregori D, Desideri A, Bigi R, et al. Proper modeling strategies selection for the assessment of post-infarction costs. Int J Cardiol. 2008;129(1):53-58.

25. Lopez-ValcarcelBG,PinillaJ.Theimpactofmedical technologyonhealth:a longitudinal analysis of ischemic heart disease. Value Health. 2008;11(1): 88-96.

26. Ringborg A, Yin DD, Martinell M, Stalhammar J, Lindgren P. The impact of acute myocardial infarction and stroke on health care costs in patients with type 2 diabetes in Sweden. Eur J Cardiovasc Prev Rehabil. 2009;16(5):576-582.

27. Wilhelmsen L, Welin L, Oden A, Bjornberg A. Saving lives, money and resources: drug and CABG/PCI use after myocardial infarction in a Swedish record-linkage study. Eur J Health Econ. 2010;11(2):177-184.

28. Ademi Z, Liew D, Hollingsworth B, et al. The economic implications of treating atherothrombotic disease in Australia, from the government perspective. Clin Ther. 2010;32(1):119-132. discussion 106-117. 
29. United Nations Statistical Divison [webpage on the Internet]. European Regions. 2013. Available from: http://unstats.un.org/unsd/default.htm. Accessed April 27, 2015.

30. Bogner HR, Miller SD, de Vries HF, Chhatre S, Jayadevappa R. Assessment of cost and health resource utilization for elderly patients with heart failure and diabetes mellitus. J Card Fail. 2010;16(6):454-460.

31. Chhatre S, Weiner MG, Jayadevappa R, Johnson JC. Incremental burden of congestive heart failure among elderly with Alzheimer's. Aging Ment Health. 2009;13(4):628-634.

32. Liao L, Anstrom KJ, Gottdiener JS, et al. Long-term costs and resource use in elderly participants with congestive heart failure in the Cardiovascular Health Study. Am Heart J. 2007;153(2):245-252.

33. Dunlay SM, Shah ND, Shi Q, et al. Lifetime costs of medical care after heart failure diagnosis. Circ Cardiovasc Qual Outcomes. 2011;4(1):68-75.

34. Trogdon JG, Finkelstein EA, Nwaise IA, Tangka FK, Orenstein D. The economic burden of chronic cardiovascular disease for major insurers. Health Promot Pract. 2007;8(3):234-242.

35. Esposito D, Bagchi AD, Verdier JM, Bencio DS, Kim MS. Medicaid beneficiaries with congestive heart failure: association of medication adherence with healthcare use and costs. Am J Manag Care. 2009;15(7):437-445.

36. Unroe KT, Greiner MA, Hernandez AF, et al. Resource use in the last 6 months of life among Medicare beneficiaries with heart failure, 2000-2007. Arch Intern Med. 2011;171(3):196-203.

37. Allen LA, Anstrom KJ, Horton JR, Shaw LK, Eisenstein EL, Felker GM. Relationship between anemia and health care costs in heart failure. J Card Fail. 2009;15(10):843-849.

38. Chen LM, Jha AK, Guterman S, Ridgway AB, Orav EJ, Epstein AM. Hospital cost of care, quality of care, and readmission rates: penny wise and pound foolish? Arch Intern Med. 2010;170(4):340-346.

39. Chen SI, Dharmarajan K, Kim N, et al. Procedure intensity and the cost of care. Circ Cardiovasc Qual Outcomes. 2012;5(3):308-313.

40. Chiong JR, Kim S, Lin J, Christian R, Dasta JF. Evaluation of costs associated with tolvaptan-mediated length-of-stay reduction among heart failure patients with hyponatremia in the US, based on the EVEREST trial. J Med Econ. 2012;15(2):276-284.

41. Gregory D, Ordway LJ, McGillivray M, Konstam MA, Denofrio D. A cost-saving strategy for inpatient management of advanced decompensated heart failure patients: the Cardiomyopathy Unit. J Card Fail. 2009; 15(5):428-434.

42. Titler MG, Jensen GA, Dochterman JM, et al. Cost of hospital care for older adults with heart failure: medical, pharmaceutical, and nursing costs. Health Serv Res. 2008;43(2):635-655.

43. Wang G, Zhang Z, Ayala C, Wall HK, Fang J. Costs of heart failurerelated hospitalizations in patients aged 18 to 64 years. Am J Manag Care. 2010;16(10):769-776.

44. Joynt KE, Orav EJ, Jha AK. The association between hospital volume and processes, outcomes, and costs of care for congestive heart failure. Ann Intern Med. 2011;154(2):94-102.

45. Shoemaker W. Variability in service line costs for heart failure and shock. Healthc Financ Manage. 2012;66(6):166.

46. Patel UD, Greiner MA, Fonarow GC, Phatak H, Hernandez AF, Curtis LH. Associations between worsening renal function and 30-day outcomes among Medicare beneficiaries hospitalized with heart failure. Am Heart J. 2010;160(1):132-138.e131.

47. Greiner MA, Hammill BG, Fonarow GC, et al. Predicting costs among Medicare beneficiaries with heart failure. Am J Cardiol. 2012;109(5):705-711.

48. Whellan DJ, Greiner MA, Schulman KA, Curtis LH. Costs of inpatient care among Medicare beneficiaries with heart failure, 2001 to 2004. Circ Cardiovasc Qual Outcomes. 2010;3(1):33-40.

49. Kociol RD, Greiner MA, Hammill BG, et al. Long-term outcomes of Medicare beneficiaries with worsening renal function during hospitalization for heart failure. Am J Cardiol. 2010;105(12):1786-1793.

50. Patterson ME, Grant WC, Glickman SW, et al. Resource use and costs of treatment with anticoagulation and antiplatelet agents: results of the WATCH trial economic evaluation. J Card Fail. 2009;15(10):819-827.
51. Reed SD, Li Y, Dunlap ME, et al. In-hospital resource use and medical costs in the last year of life by mode of death (from the HF-ACTION randomized controlled trial). Am J Cardiol. 2012;110(8):1150-1155.

52. Chan PS, Soto G, Jones PG, et al. Patient health status and costs in heart failure: insights from the eplerenone post-acute myocardial infarction heart failure efficacy and survival study (EPHESUS). Circulation. 2009;119(3):398-407.

53. Caporale JE, Elgart J, Pfirter G, et al. Hospitalization costs for heart failure in people with type 2 diabetes: cost-effectiveness of its prevention measured by a simulated preventive treatment. Value Health. 2011;14(5 suppl 1):S20-S23.

54. Kaul P, McAlister FA, Ezekowitz JA, et al. Resource use in the last 6 months of life among patients with heart failure in Canada. Arch Intern Med. 2011;171(3):211-217.

55. Dilokthornsakul P, Chaiyakunapruk N, Nimpitakpong P, Jeanpeerapong N, Sruamsiri R. The effects of medication supply on hospitalizations and health-care costs in patients with chronic heart failure. Value Health. 2012;15(1 suppl):S9-S14.

56. Ellis C. Stroke in young adults. Disabil Health J. 2010;3(3):222-224.

57. Ellis C, Simpson AN, Bonilha H, Mauldin PD, Simpson KN. The one-year attributable cost of poststroke aphasia. Stroke. 2012;43(5): 1429-1431.

58. Engel-Nitz NM, Sander SD, Harley C, Rey GG, Shah H. Costs and outcomes of noncardioembolic ischemic stroke in a managed care population. Vasc Health Risk Manag. 2010;6:905-913.

59. Kind AJ, Smith MA, Liou JI, Pandhi N, Frytak JR, Finch MD. The price of bouncing back: one-year mortality and payments for acute stroke patients with 30-day bounce-backs. J Am Geriatr Soc. 2008;56(6): 999-1005.

60. Lee WC, Christensen MC, Joshi AV, Pashos CL. Long-term cost of stroke subtypes among Medicare beneficiaries. Cerebrovasc Dis. 2007;23(1):57-65.

61. Mahoney EM, Wang K, Cohen DJ, et al. One-year costs in patients with a history of or at risk for atherothrombosis in the United States. Circ Cardiovasc Qual Outcomes. 2008;1(1):38-45.

62. Roberts CS, Gorelick PB, Ye X, Harley C, Goldberg GA. Additional stroke-related and non-stroke-related cardiovascular costs and hospitalizations in managed-care patients after ischemic stroke. Stroke. 2009;40(4):1425-1432.

63. Zorowitz RD, Chen E, Tong KB, Laouri M. Costs and rehabilitation use of stroke survivors: a retrospective study of Medicare beneficiaries. Top Stroke Rehabil. 2009;16(5):309-320.

64. Bruggenjurgen B, Rossnagel K, Roll S, et al. The impact of atrial fibrillation on the cost of stroke: the berlin acute stroke study. Value Health. 2007;10(2):137-143.

65. Christensen MC, Munro V. Ischemic stroke and intracerebral hemorrhage: the latest evidence on mortality, readmissions and hospital costs from Scotland. Neuroepidemiology. 2008;30(4):239-246.

66. Ghatnekar O, Glader EL. The effect of atrial fibrillation on strokerelated inpatient costs in Sweden: a 3-year analysis of registry incidence data from 2001. Value Health. 2008;11(5):862-868.

67. Luengo-Fernandez R, Gray AM, Rothwell PM; Oxford Vascular Study. A population-based study of hospital care costs during 5 years after transient ischemic attack and stroke. Stroke. 2012;43(12): 3343-3351.

68. Mahler MP, Zuger K, Kaspar K, et al. A cost analysis of the first year after stroke - early triage and inpatient rehabilitation may reduce long term costs. Swiss Med Wkly. 2008;138(31-32):459-465.

69. McGuire AJ, Raikou M, Whittle I, Christensen MC. Long-term mortality, morbidity and hospital care following intracerebral hemorrhage: an 11-year cohort study. Cerebrovasc Dis. 2007;23(2-3):221-228.

70. Meretoja A, Kaste M, Roine RO, et al. Direct costs of patients with stroke can be continuously monitored on a national level: performance, effectiveness, and Costs of Treatment episodes in Stroke (PERFECT Stroke) Database in Finland. Stroke. 2011;42(7):2007-2012.

71. Thijs V, Dewilde S, Putman K, Pince H. Cost of hospitalization for cerebrovascular disorders in Belgium. Acta Neurol Belg. 2011;111(2): $104-110$. 
72. Winter Y, Wolfram C, Schaeg M, et al. Evaluation of costs and outcome in cardioembolic stroke or TIA. J Neurol. 2009;256(6):954-963.

73. Gioldasis G, Talelli P, Chroni E, Daouli J, Papapetropoulos T, Ellul J. In-hospital direct cost of acute ischemic and hemorrhagic stroke in Greece. Acta Neurol Scand. 2008;118(4):268-274.

74. Ma Y, Liu Y, Fu HM, et al. Evaluation of admission characteristics, hospital length of stay and costs for cerebral infarction in a mediumsized city in China. Eur J Neurol. 2010;17(10):1270-1276.

75. Sun Y, Toh MP. Impact of diabetes mellitus (DM) on the health-care utilization and clinical outcomes of patients with stroke in Singapore. Value Health. 2009;12(suppl 3):S101-S105.

76. Wang IK, Muo CH, Chang YC, et al. Risks, subtypes, and hospitalization costs of stroke among patients with systemic lupus erythematosus: a retrospective cohort study in Taiwan. $J$ Rheumatol. 2012;39(8):1611-1618.

77. Wei JW, Heeley EL, Jan S, et al. Variations and determinants of hospital costs for acute stroke in China. PLoS One. 2010;5(9):e13041.

78. Christensen MC, Previgliano I, Capparelli FJ, Lerman D, Lee WC, Wainsztein NA. Acute treatment costs of intracerebral hemorrhage and ischemic stroke in Argentina. Acta Neurol Scand. 2009;119(4):246-253.

79. Christensen MC, Valiente R, Sampaio Silva G, et al. Acute treatment costs of stroke in Brazil. Neuroepidemiology. 2009;32(2):142-149.

80. Mittmann N, Seung SJ, Hill MD, et al. Impact of disability status on ischemic stroke costs in Canada in the first year. Can J Neurol Sci. 2012;39(6):793-800.

81. Auerbach AD, Hilton JF, Maselli J, Pekow PS, Rothberg MB, Lindenauer PK. Case volume, quality of care, and care efficiency in coronary artery bypass surgery. Arch Intern Med. 2010;170(14):1202-1208.

82. Birkmeyer JD, Gust C, Dimick JB, Birkmeyer NJ, Skinner JS. Hospital quality and the cost of inpatient surgery in the United States. Ann Surg. 2012;255(1): $1-5$.

83. Chastek B, Riedel AA, Wygant G, Hauch O. Evaluation of hospitalization and follow-up care costs among patients hospitalized with ACS treated with a stent and clopidogrel. Curr Med Res Opin. 2009;25(12):2845-2852.

84. Chen JC, Kaul P, Levy JH, et al. Myocardial infarction following coronary artery bypass graft surgery increases healthcare resource utilization. Crit Care Med. 2007;35(5):1296-1301.

85. Eisenstein EL, Sun JL, Anstrom KJ, DeLong ER, Szczech LA, Mark DB. Assessing the economic attractiveness of coronary artery revascularization in chronic kidney disease patients. $J$ Med Syst. 2009;33(4):287-297.

86. Eisenstein EL, Wijns W, Fajadet J, et al. Long-term clinical and economic analysis of the Endeavor drug-eluting stent versus the Driver bare-metal stent: 4-year results from the ENDEAVOR II trial (Randomized Controlled Trial to Evaluate the Safety and Efficacy of the Medtronic AVE ABT-578 Eluting Driver Coronary Stent in De Novo Native Coronary Artery Lesions). JACC Cardiovasc Interv. 2009;2(12):1178-1187.

87. Hlatky MA, Boothroyd DB, Melsop KA, et al. Economic outcomes of treatment strategies for type 2 diabetes mellitus and coronary artery disease in the Bypass Angioplasty Revascularization Investigation 2 Diabetes trial. Circulation. 2009; 120(25):2550-2558.

88. Johnston SS, Bell K, Gdovin J, Jing Y, Graham J. Coronary artery bypass graft surgery in acute coronary syndrome: incidence, cost impact, and acute clopidogrel interruption. Hosp Pract (1995). 2012;40(1):15-23.

89. Kessler DP, Kroch E, Hlatky MA. The effect of bivalirudin on costs and outcomes of treatment of ST-segment elevation myocardial infarction. Am Heart J. 2011;162(3):494-500.e492.

90. LaPar DJ, Bhamidipati CM, Reece TB, Cleveland JC, Kron IL, Ailawadi G. Is off-pump coronary artery bypass grafting superior to conventional bypass in octogenarians? JThorac Cardiovasc Surg. 2011;141(1):81-90.

91. LaPar DJ, Stukenborg GJ, Guyer RA, et al. Primary payer status is associated with mortality and resource utilization for coronary artery bypass grafting. Circulation. 2012;126(11 suppl 1):S132-S139.

92. Lindsey JB, Cohen DJ, Stolker JM, et al. The impact of bivalirudin on percutaneous coronary intervention-related bleeding. EuroIntervention. 2010;6(2):206-213.
93. Mark DB, Knight JD, Velazquez EJ, et al. Quality of life and economic outcomes with surgical ventricular reconstruction in ischemic heart failure: results from the Surgical Treatment for Ischemic Heart Failure trial. Am Heart J. 2009;157(5): 837-844, 844.e831-833.

94. Olchanski N, Slawsky KA, Plent S, Kado C, Cyr PL. Economic impact of switching to bivalirudin for a primary percutaneous coronary intervention in a US hospital. Hosp Pract (1995). 2010;38(4):138-146.

95. Philipson TJ, Mozaffari E, Maclean JR. Pharmacy cost sharing, antiplatelet therapy utilization, and health outcomes for patients with acute coronary syndrome. Am J Manag Care. 2010;16(4):290-297.

96. Pinto DS, Stone GW, Shi C, et al. Economic evaluation of bivalirudin with or without glycoprotein IIb/IIIa inhibition versus heparin with routine glycoprotein IIb/IIIa inhibition for early invasive management of acute coronary syndromes. $\mathrm{J} \mathrm{Am} \mathrm{Coll} \mathrm{Cardiol.}$ 2008;52(22):1758-1768.

97. Poston RS, Tran R, Collins M, et al. Comparison of economic and patient outcomes with minimally invasive versus traditional off-pump coronary artery bypass grafting techniques. Ann Surg. 2008;248(4):638-646.

98. Rihal CS, Ryan JL, Singh M, et al. Clinical and economic outcomes after introduction of drug-eluting stents. Am J Manag Care. 2010;16(8): $580-587$.

99. Ryan J, Linde-Zwirble W, Engelhart L, Cooper L, Cohen DJ. Temporal changes in coronary revascularization procedures, outcomes, and costs in the bare-metal stent and drug-eluting stent eras: results from the US Medicare program. Circulation. 2009;119(7):952-961.

100. Saleh SS, Racz M, Hannan E. The effect of preoperative and hospital characteristics on costs for coronary artery bypass graft. Ann Surg. 2009;249(2):335-341.

101. Speir AM, Kasirajan V, Barnett SD, Fonner E Jr. Additive costs of postoperative complications for isolated coronary artery bypass grafting patients in Virginia. Ann Thorac Surg. 2009;88(1):40-45. discussion 45-46.

102. Vogel TR, Dombrovskiy VY, Lowry SF. In-hospital delay of elective surgery for high volume procedures: the impact on infectious complications. J Am Coll Surg. 2010;211(6):784-790.

103. Bakhai A, Ferrieres J, Iniguez A, et al. Clinical outcomes, resource use, and costs at 1 year in patients with acute coronary syndrome undergoing PCI: results from the multinational APTOR registry. $J$ Interv Cardiol. 2012;25(1):19-27.

104. Bramkamp M, Radovanovic D, Erne P, Szucs TD. Determinants of costs and the length of stay in acute coronary syndromes: a real life analysis of more than 10,000 patients. Cardiovasc Drugs Ther. 2007;21(5):389-398.

105. Dendale P, Hansen D, Berger J, Lamotte M. Long-term cost-benefit ratio of cardiac rehabilitation after percutaneous coronary intervention. Acta Cardiol. 2008;63(4):451-456.

106. Epstein DM, Sculpher MJ, Clayton TC, et al. Costs of an early intervention versus a conservative strategy in acute coronary syndrome. Int J Cardiol. 2008;127(2):240-246.

107. Friedel H, Delges A, Clouth J, Trautvetter DT. Expenditures of the German statutory health insurance system for patients suffering from acute coronary syndrome and treated with percutaneous coronary intervention. Eur J Health Econ. 2010;11(5):449-455.

108. Gaughan J, Kobel C, Linhart C, et al; EuroDRG Group. Why do patients having coronary artery bypass grafts have different costs or length of stay? An analysis across 10 European countries. Health Econ. 2012;21(suppl 2):77-88.

109. Kastanioti C. Costs, clinical outcomes, and health-related quality of life of off-pump vs. on-pump coronary bypass surgery. Eur J Cardiovasc Nurs. 2007;6(1):54-59.

110. Odell A, Landelius P, Astrom-Olsson K, Grip L. The impact of general usage of stents on short- and long-term health care costs following percutaneous coronary intervention. Cardiology. 2008;109(2): 85-92.

111. Varani E, Balducelli M, Vecchi G, Aquilina M, Maresta A. One-year clinical results and total costs of drug-eluting stents implantation in multivessel coronary artery disease. J Cardiovasc Med (Hagerstown). 2007;8(8):596-601. 
112. Varani E, Balducelli M, Vecchi G, Aquilina M, Maresta A. Comparison of multiple drug-eluting stent percutaneous coronary intervention and surgical revascularization in patients with multivessel coronary artery disease: one-year clinical results and total treatment costs. J Invasive Cardiol. 2007;19(11):469-475.

113. Forouzannia SK, Abdollahi MH, Mirhosseini SJ, et al. Clinical outcome and cost in patients with off-pump vs. on-pump coronary artery bypass surgery. Acta Med Iran. 2011;49(7):414-419.

114. Hu S, Li Q, Gao P, et al. Simultaneous hybrid revascularization versus off-pump coronary artery bypass for multivessel coronary artery disease. Ann Thorac Surg. 2011;91(2):432-438.

115. Hu S, Zheng Z, Yuan X, et al. Increasing long-term major vascular events and resource consumption in patients receiving off-pump coronary artery bypass: a single-center prospective observational study. Circulation. 2010;121(16):1800-1808.

116. Noguchi H, Shimizutani S, Masuda Y. Regional variations in medical expenditure and hospitalization days for heart attack patients in Japan: evidence from the Tokai Acute Myocardial Study (TAMIS). Int J Health Care Finance Econ. 2008;8(2):123-144.

117. Sakakura K, Ako J, Wada H, Kubo N, Momomura S. Comparison of the resource utilization between simultaneous strategy and staged strategy to treat two-vessel coronary artery disease by percutaneous coronary intervention. J Invasive Cardiol. 2011;23(11): 454-459.

118. Shimizu T, Ohno T, Ando J, et al. Mid-term results and costs of coronary artery bypass vs drug-eluting stents for unprotected left main coronary artery disease. Circ J. 2010;74(3):449-455.

119. Zhao FH, Lu SZ, Li H, et al. Clinical outcomes and cost-utility after sirolimus-eluting versus bare metal stent implantation. Chin Med J (Engl). 2010;123(20):2797-2802.
120. Girardi PB, Hueb W, Nogueira CR, et al. Comparative costs between myocardial revascularization with or without extracorporeal circulation. Arq Bras Cardiol. 2008;91(6):340-346.

121. Haddad N, Bittar E, de Marchi AF, et al. Hospital costs of coronary artery bypass grafting on elective coronary patients. Arq Bras Cardiol. 2007;88(4):418-423.

122. Rodriguez AE, Maree A, Tarragona S, et al. Percutaneous coronary intervention with oral sirolimus and bare metal stents has comparable safety and efficacy to treatment with drug eluting stents, but with significant cost saving: long-term follow-up results from the randomised, controlled ORAR III (Oral Rapamycin in ARgentina) study. EuroIntervention. 2009;5(2):255-264.

123. Arnold SV, Morrow DA, Lei Y, et al. Economic impact of angina after an acute coronary syndrome: insights from the MERLIN-TIMI 36 trial. Circ Cardiovasc Qual Outcomes. 2009;2(4):344-353.

124. Cohen DJ, Lavelle TA, Van Hout B, et al. Economic outcomes of percutaneous coronary intervention with drug-eluting stents versus bypass surgery for patients with left main or three-vessel coronary artery disease: one-year results from the SYNTAX trial. Catheter Cardiovasc Interv. 2012;79(2):198-209.

125. Rinfret S, Kennedy WA, Lachaine J, et al. Economic impact of sameday home discharge after uncomplicated transradial percutaneous coronary intervention and bolus-only abciximab regimen. JACC Cardiovasc Interv. 2010;3(10):1011-1019.

126. Payne KA, Huybrechts KF, Caro JJ, Craig Green TJ, Klittich WS. Long term cost-of-illness in stroke: an international review. Pharmacoeconomics. 2002;20(12):813-825.

127. Reynolds MW, Frame D, Scheye R, et al. A systematic review of the economic burden of chronic angina. Am J Manag Care. 2004;10(11 suppl): S347-S357.
ClinicoEconomics and Outcomes Research

\section{Publish your work in this journal}

ClinicoEconomics and Outcomes Research is an international, peerreviewed open-access journal focusing on health technology assessment, pharmacoeconomics and outcomes research in the areas of diagnosis, medical devices, and clinical, surgical and pharmacological intervention. The economic impact of health policy and health systems
Submit your manuscript here: https://www.dovepress.com/clinicoeconomics-and-outcomes-researh-our

organization also constitute important areas of coverage. The manuscript management system is completely online and includes a very quick and fair peer-review system, which is all easy to use. Visit http://www.dovepress.com/testimonials.php to read real quotes from published authors. 